\title{
Retraction Note to: A comprehensive analysis of candidate genes and pathways in pancreatic cancer
}

\author{
Jie Liu ${ }^{1} \cdot{\mathrm{Jun} \mathrm{Li}^{1}}^{1} \cdot \mathrm{Hali}{ }^{1} \cdot \operatorname{Aidong} \mathrm{Li}^{1} \cdot \mathrm{Biou} \mathrm{Liu}^{1} \cdot \operatorname{Liou} \mathrm{Han}^{1}$
}

Published online: 17 August 2015

(C) International Society of Oncology and BioMarkers (ISOBM) 2015

Retraction Note to: Tumor Biol. (2015) 36:1849-1857

DOI 10.1007/s13277-014-2787-y

The Publisher and Editor retract this article in accordance with the recommendations of the Committee on Publication Ethics (COPE). After a thorough investigation we have strong reason to believe that the peer review process was compromised.

The online version of the original article can be found at http://dx.doi.org/ 10.1007/s13277-014-2787-y.

Biou Liu

WeidongZangwtr@163.com

1 Department of general surgery, The First Affiliated Hospital of Harbin Medical University, No.23, Youzheng Street, Nangang

District, Harbin 150001, China 